\title{
Representing IT Performance Management as Metamodel
}

\author{
A. Pajić, O. Pantelić, B. Stanojević
}

\author{
Ana Pajić $\tilde{c}^{*}$ Ognjen Pantelić \\ Department of Information Systems \\ Faculty of Organizational Sciences, University of Belgrade \\ Jove Ilica 154, 11000 Belgrade, Serbia \\ ana.pajic@fon.bg.ac.rs, pantelico@fon.bg.ac.rs \\ *Corresponding author \\ Bogdana Stanojević \\ Mathematical Institute of the Serbian Academy of Sciences and Arts \\ Kneza Mihaila 36, 11000 Belgrade, Serbia \\ bgdnpop@mi.sanu.ac.rs
}

\begin{abstract}
Many empirical studies have shown that the business value from investment in IT projects can be greater than the one being currently achieved. Thus it calls for specific focus on IT governance in order to reach fusion between business and IT goals. Good IT performance management should enable the business and IT executives to understand how IT is contributing to the achievement of business goals. The paper addresses the issue of representing IT governance best practice frameworks as ontological metamodels. Special attention is dedicated to VAL IT framework, which represents a comprehensive framework to maximize business value from IT investments. The paper points out the necessity of analyzing, comparing and integrating IT governance frameworks in order to complement different knowledge and generate ontological metamodel of IT performance management. Scope of our work is in the static aspect of the framework and as the metalanguage Extended Entity/Relationship model is used.

Keywords: IT governance, ontology, metamodels, IT investment, IT performance management.
\end{abstract}

\section{Introduction}

In today's changing and competitive business environment, organizations are in a constant struggle to obtain a dominant role in the market. Information technology (IT) has become a key enabler of business process reengineering if an organization is to survive and continue to prosper. They invest substantial financial resources for delivering quality software as their competitive advantage. The increasing use of information technology (IT) has resulted in a need for evaluating the productivity impact of IT. Many empirical studies have shown that the business value from investment in IT projects can be greater than the one being currently achieved [8]. More investments do not mean by design achieving desired goals and better business results. It refers to productivity paradox, initially formulated by Solow [20] in 1987, who pointed out "You can see the computer age everywhere but in the productivity statistics". Thus it calls for specific focus on IT governance in order to achieve fusion between business and IT.

Several studies reported rather low success rates in achieving successful business and IT alignment on the organization level, as perceived by business and IT executives [18]. Figures run so low that they are ranked as one of the top concerns for the upper management, in the last few years. One way to reach the strategic alignment and to bridge the gap between business and IT is through the way companies govern their IT. Effective IT governance is seen as a critical element to ensure returns on IT investment and improved organizational performance [12]. 
This can be achieved through creation of organizational structure with clearly defined roles and responsibilities regarding information, business processes, applications and IT infrastructure. It can contribute to higher returns on assets with the main goal to provide the support for conducting business in a good manner [19]. Strong emphasis is now placed on developing IT governance frameworks to help the management to ensure that organizations realize optimal value from IT business investments at an affordable cost with a known and acceptable level of risk. ITIL (Information Technology Infrastructure Library) and COBIT (Control Objectives for Information and related Technologies) are recognized in the business and academic world as the most used and adopted frameworks ( [4], [7]). However, there are a lot of concerns in regard to adaption and integration of different best practice frameworks, which subsequently bring the logical structures and semantic of the frameworks in forefront.

Achieving IT business value and measuring that value are important governance domains. Good IT performance management should enable the business and IT executives to understand how IT contributes to the achievement of business goals, in the past and in the future. As Brandabur [3] pointed out "the IT capability of organization exceeds many concepts like strengths or competitive advantage and had become an absolute necessity". A focus of IT performance management should be the removal of non-value adding activities and processes. According to Haanappel et al. [9], organizations had very different IT performance management approaches and maturity levels. IT performance measurement framework needs to be balanced, comprehensive and adopted as the tool for evaluation and assessment of IT investments. Therefore, the research will address this issue. Paper goal is to provide insight into semantically rich structure of best practice frameworks for supporting management and governance of IT. Special attention is dedicated to Val IT framework, which represents a comprehensive framework to maximize business value from IT investments. Moreover, the integration of different IT best practice frameworks will result in generating ontological metamodel of IT performance management framework.

In Section 2 we discuss the concept of metamodel and ontology from the academic perspective, and elaborate the IT performance management concept. A new ontological metamodel of VAL IT framework, with rich logical structure and semantics of its relationships, is introduced in Section 3. An ontological metamodel for monitoring IT performance is presented in Section 4 to complete the models of IT governance best practices. In Section 5, we discuss research outcomes and ideas for future work.

\section{Related Works and Basic Concepts}

\subsection{Metamodels and Ontologies}

Models as the main instruments of enterprise architecture (EA) have been very useful in addressing IT/business alignment problems [17]. The objective of EA is to enable organization to align business goals and IT investment plans. EA models are striving to be executable in order to enable enterprise to adapt IT and enterprise models to change situations and to increase business opportunities.

Models on different levels of abstraction are in existence today. At a higher-level of abstraction "model of model" is called metamodel. Metamodels play an important role in EA by ensuring semantic consistency and a common language for the enterprise [6]. Atkinson and Kühn [2] have come to the conclusion of two dimensions of metamodeling: linguistic and ontological. The difference between them is in the forms of instancing the objects of the metamodel. Linguistic metamodeling deals with the definition of the language and relationships between its elements. On the other hand, ontological metamodels are related to the classification of model elements according to their content. They cope with "instance of" relationships between concepts and 
their types. Ontological metamodels are more oriented to the users, focusing on content instead of forms.

Keeping in mind a note of Karagiannis [13] that the combination of metamodels and ontologies provides a solution of fully semantic integration, we present in this paper a VAL IT framework and IT performance management framework as a semantic enrichment metamodels. The scope of our work is in static aspect of the frameworks and as the metalanguage the Extended Entity/Relationship model is used [5]. The data is presented in following types: entity, relationship, attribute and constructor.

\subsection{IT Governance Frameworks}

The problem of implementing the IT best practice frameworks is receiving growing attention from scientists. IT governance has emerged as an answer to the problem of identifying the business value derived from investments in IT. In order to provide the business value, investment in information technology and systems has to be closely aligned to the corporate strategy. "By creating the necessary structures and processes around IT investments, management can ensure that only those IT projects that are aligned with strategic business objectives are approved, funded, and prioritized" highlighted Symons in [21]. Webb et al. [22] underlined performance and risk management as essential part of IT governance. Moreover, their study has proven that companies with good IT governance model generate higher results than competitors.

Nowadays, COBIT and ITIL are the best known and widely accepted best practices. ITIL represents set of practices focusing on aligning IT services with the needs of businesses. It has become the standard for IT service management (ITSM), providing "a detailed description of a number of important IT practices, with comprehensive checklists, tasks, procedures, and responsibilities, which can be tailored to any IT organization" [15]. On the other hand, COBIT pays more attention on audit and control perspective. In addition it provides maturity models, Critical Success Factors and different metrics [11]. Pereira and Mira da Silva [16] presented in their work the conceptual models of both frameworks, highlighting the fact: "a very complex framework with several dependencies between processes". Moreover, the COBIT metamodel can be found in the literature [7] and in the following we will focus on it. At the heart of COBIT are 34 processes which are grouped into four life cycle domains: Plan and Organize (PO), Acquire and Implement (AI), Deliver and Support (DS), Monitor and Evaluate (ME). Each of these 34 processes has goals, divided into activity, process and IT goals. It is well-structured and therefore applicable for semantic metamodeling.

The main contribution of the presented model is reflected in identifying the possibilities of framework improvement. For example, the authors realize that the component's activity and the control objective are both connected to the process, but not related to one another. They consider that control objectives have significant overlapping with activities and it can be eliminated by dropping the relationship between activity and process. Furthermore, new processes can be integrated in the framework, which has substantial impact on the model flexibility.

The further subject of this research will be VAL IT framework, developed and maintained by the IT Governance Institute. It sets good practices for the process of value creation. Val IT framework is primarily designed to complement COBIT, but it can be used without a prior implementation of COBIT framework.

\subsection{IT Performance Management}

Measuring IT performance ensures that organizations maximize the business value of their IT investments. IT performance management can be defined as the area of setting goals, responsibility accounting and monitoring and improving the performance of IT [9]. Four key areas of 
IT performance management are recognized by Andra [1]. The two most important areas are IT efficiency and effectiveness. According to Kifor and Tudor [14], IT effectiveness and efficiency represents today some of the most important Key Performance Indicators and a permanent concern for every organization. Many methods, tools and best practices exist to demonstrate the added business value of IT. Problems in measuring IT performance emerge when traditional financial methods are applied to information systems, which often generate intangible benefits. Despite a number of well-established methods available in the market, they are not widely adopted among IT and business executives in evaluation of IT performance. A limited amount of literature is available on how an organization can apply and improve their IT performance management. It is necessary to understand in depth framework's complex structure and purpose with the aim to adopt framework and using it in practice.

\section{The Metamodel of VAL IT Framework}

In the age of information and knowledge, it is no longer sufficient to measure only financial performance, but instead it is necessary to determine the value of intangible assets. From an IT governance point of view, evaluating the business value of IT investments is of high importance in order to control, govern and manage IT functions. As a comprehensive framework, VAL IT is dedicated to answer this issue with the primary goal to maximize business value from IT investments. According to the ITGI, VAL IT "adds best practices for the end, providing the means to unambiguously measure, monitor and optimize the realization of business value from investment in IT". It is systematic and comprehensive approach for measuring and delivering value, which represents one of the five focus areas of IT governance. Val IT supports organization by providing clear and consistent policy to improve IT investments decisions and returns on investments.

The framework covers the value governance processes and management practices, portfolio and investment management, with ongoing measurements. They represent the three main domains. Each domain includes a number of processes, key management practices and activities that need to occur in order to select the investments with the highest potential to create value and to manage them. Twenty two processes are contained in these domains. Each process produces specific outputs and delivers it to other processes as their inputs. Therefore, both of them are categorized as results and presented through specialization relationship type. Two types of output benefits are distinguished in VAL IT framework. The first are business benefits which influence value directly to. On the contrary, intermediate benefits do not create value despite they might fulfill stakeholders' needs. Thus, we link outputs to the concept stakeholder. Furthermore, process is decomposed to activities and for each activity it is indicated who should be responsible, accountable, consulted and informed (RACI chart). Responsibilities and accountabilities are defined for typical roles. The stated categories might be assigned to one or more of these roles, which might be undertaken by one person or single organization entity in smaller enterprises. Categories are identified as entity and its relationship with role and activity entities is treated as higher-level entity, assignment aggregation.

The VAL IT management guidelines illustrate possible assignments of responsibilities to different roles. Furthermore for each VAL IT process, guidelines include key activities that need to be assumed, activity description, inputs and outputs. Besides, VAL IT processes are collection of practices, including activities and procedures. Within the processes, a set of key management practices are introduced as main characteristics which lead to success. Hence, the process entity is in relationship with management guidelines and management practice entities. It contains management practices and is supported by management guidelines. There are three types of goals and metrics defined for corresponding levels for each of the processes. Domain 
goals and metrics describe what has to be done in order to deliver optimal value from ITenabled business investments. In addition, they were enabled to achieve process goals which are measured by process metrics. The process goals and metrics have been influenced by the process key management practices. Activity goals and metrics are established by process goals and they need to occur inside each process. It is important to measure what has actually been achieved, before outcome is met and afterwards. Maturity level is assigned to each of three domains, based on particular maturity model. Maturity model is given to help enterprise identify its current state and possible future states. The point is to set the priorities for further improvements.

The most important component of Val IT is business case, which is essential for ensuring additional value from business changes. Selecting the right investments closely depends on well defined and comprehensive business case. Business case includes different business processes and a set of assumptions how value will be created. They guarantee expected outcomes based on the major IT input recourses. In addition, business case should be based on key indicators, both financial and non-financial.

Figure 1 shows our ontological metamodel of VAL IT.

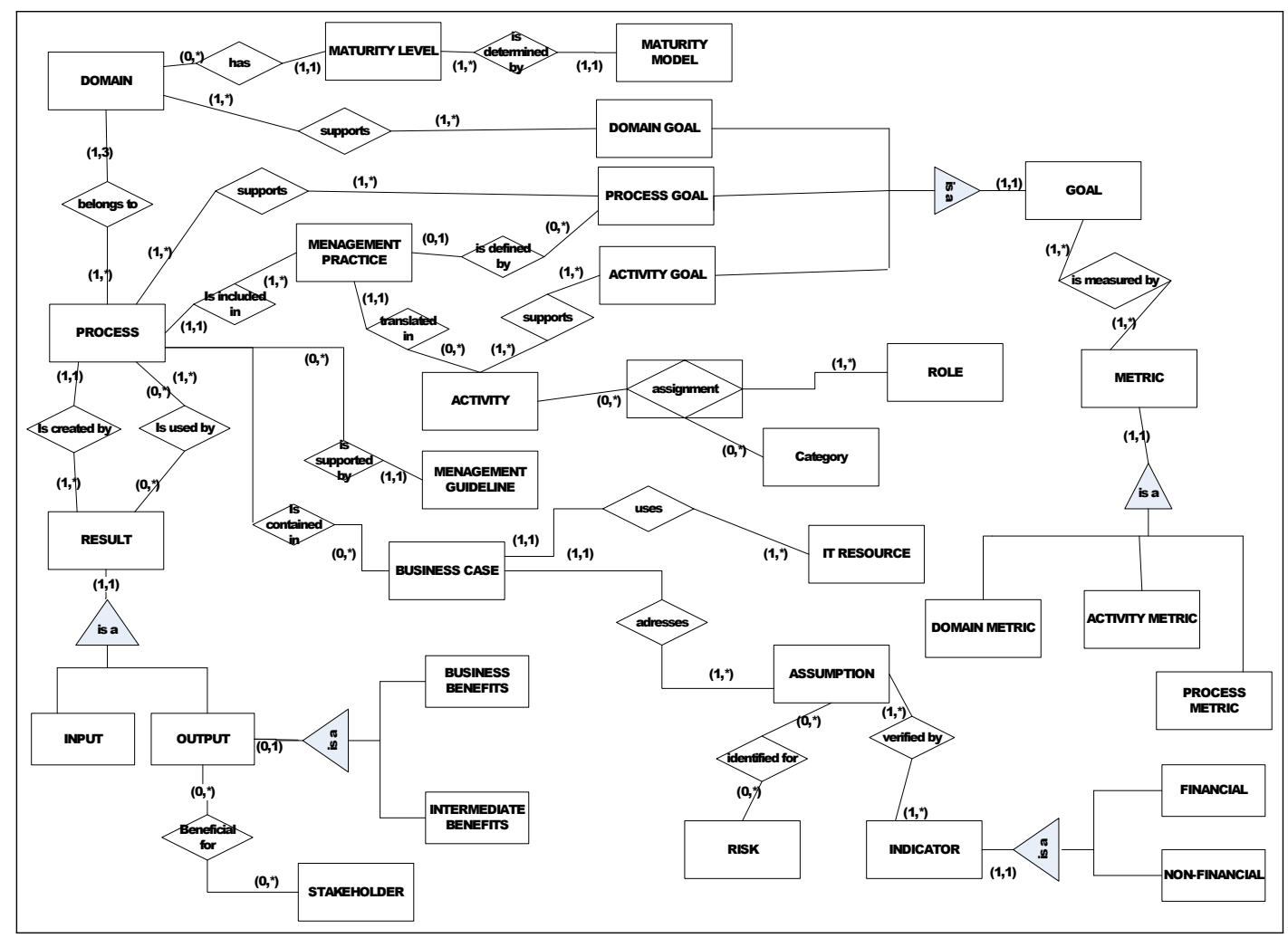

Figure 1: Ontological metamodel of VAL IT

\section{IT Performance Management Metamodel}

Although there are a great number of methodologies, from quantitative metric ROI, to higher qualitative metric of the IT Balanced Scorecard, there is not the best possible solution or a standard for measuring the value of IT. Simple ROI or other financial metrics are not good enough. Therefore, a comprehensive IT performance management framework will ensure that organization significantly improve their IT investment returns based on projected business value as well as the actual value delivered. 
As we mentioned before, the ontological metamodels represent an adequate tool for the analysis, adaptation and integration of best practices in governance of IT. We analyzed the best known and widely accepted IT governance frameworks with focus on COBIT framework in Section 2 of the paper. Different kinds of metrics, such as Key Performance Indicators (KPI), Key Goal Indicators (KGI), and Critical Success Factors (CSF), are suggested in widely accepted IT governance framework COBIT in order to monitor the implementation of each process [7]. VAL IT framework complements the earlier established and used COBIT, going one step forward in setting good practices for the process of value creation. It includes portfolio and investment management processes with ongoing measurements. Therefore, we presented VAL IT framework as ontological metamodel in Section 3, with the idea to analyze and compare these two frameworks in order to generate one comprehensive ontological metamodel of IT performance management framework. Despite different focuses and logical structures, these two frameworks are enough compatible to be compared and integrated in order to generate one comprehensive ontological IT performance management metamodel. Connections between the components of the frameworks are found after performing in-depth analysis of the metamodels. Entity types, such us Process, Activity, Goal, Metric and Maturity model, have similar meanings and attributes in these frameworks. The study covers only the components in the IT performance management domain. Furthermore, the new elements are integrated in the metamodel as the improvement of IT governance best practice frameworks.

The starting point of metamodel is the entity type Business case, essential for ensuring additional value from IT investments. Business case includes different processes and assumptions of how value will be created. For IT performance management it is important to evaluate expected outcomes of business case through different milestones. A milestone is a significant event, which belongs to a business case and is used to monitor the progress in achievement of a particular outcome. The relationship between entity types Milestone and Expected outcome implies that a milestone is used as the checkpoint only for one outcome. Reading the relationship the other way around shows that one outcome has been evaluated through one or more milestones. COBIT is frequently used as the standard for IT governance maturity assessment. In order to apply it as a tool to assess IT performance a lot of expert knowledge is needed. There are lots of metrics, but little support for improving decision-making process. Combining maturity models elements of both frameworks, we have defined elements Maturity model and Maturity level for business case. The reason for assessing maturity of business case lies in the fact that it is active during the whole economic life cycle of investments.

The following IT performance management concepts are defined: Critical Success Factor (CSF), Key Performance Indicator (KPI) and Key Risk Indicator (KRI). They are defined by management guidelines of COBIT and Val IT frameworks. CSFs are elements vital for business case to be successful. Each CSF refers to the milestone and is supported by KPIs and KRIs. The concept of key risk indicator is introduced and it supports process of risk assessment. Relationship between entity types CSF and KPI is treated as higher level entity, aggregation with Rating criteria as attribute. The same type of relationship is defined among entity types CSF and KPI. In addition, business case should be based on KPIs, both financial and non-financial. The relationship between employee and KPI implies that an employee is responsible for zero or more Key Performance Indicators. Reading the relationship the other way around shows that a KPI can belong to only one employee. KPI owner is responsible for proactive monitoring of results progress and creation of KPI evaluation report, which can lead to actions of improvement. One action can be caused by only one KPI evaluation report according to metamodel. It is important to emphasize the difference between metric and KPI concepts. KPI is a metric, but metric is not necessarily a KPI. The cardinality of relationship defines this limitation. There are three types of goals and metrics defined for corresponding level in business case. Process goals and 
metrics describe what has to be done in order to deliver optimal value from IT-enabled business investments. The Activity goals and metrics are established by process goals and they need to occur inside each process. In addition, IT goal is introduced with the aim to succeed IT and business alignment. Both concepts are presented through specialization relationship type. The relationship between entity types Goal and Metric is treated as higher level entity, aggregation with Score as attribute. A metamodel of IT performance management framework is presented in Figure 2.

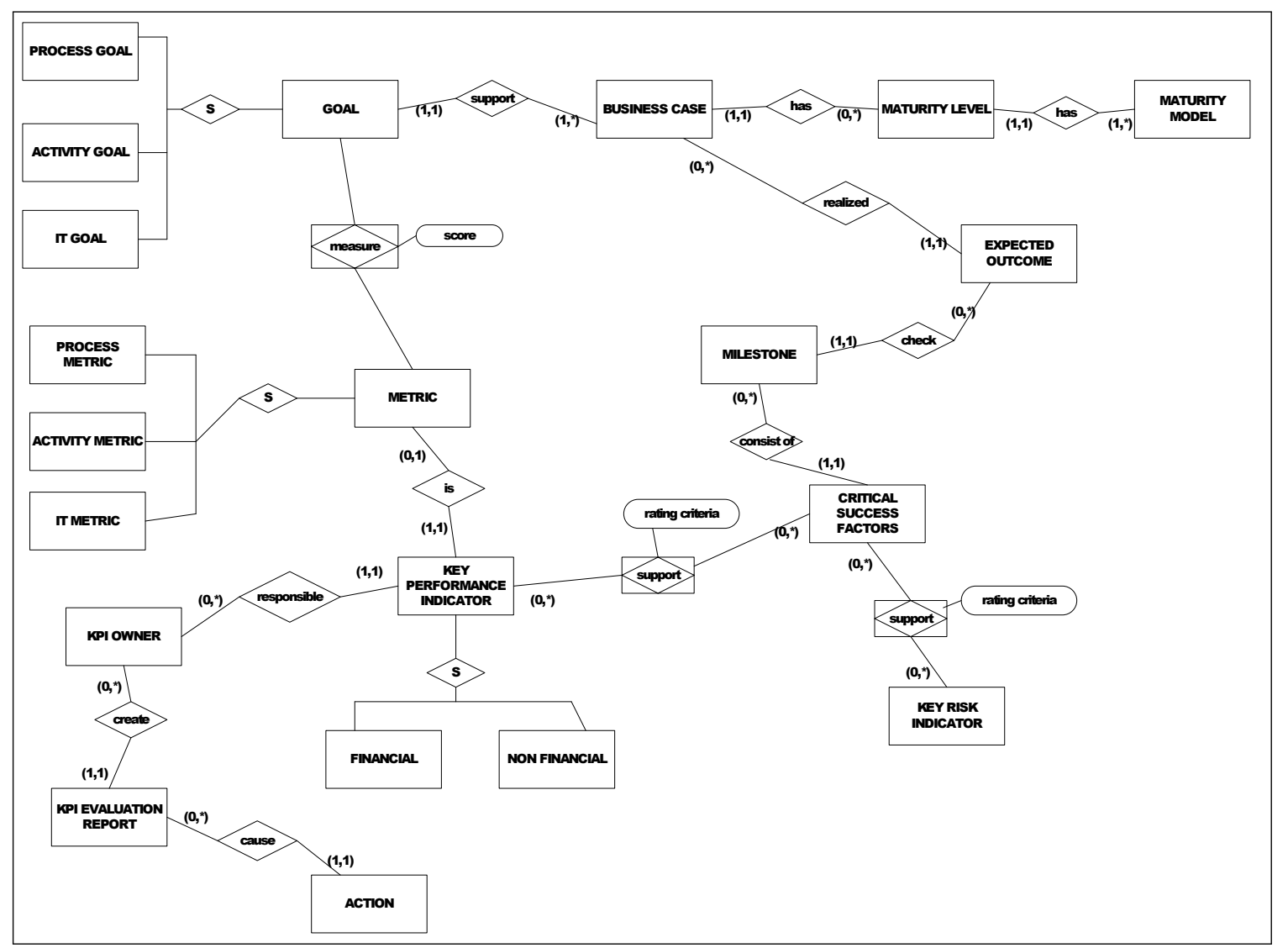

Figure 2: IT performance management ontological metamodel

\section{Conclusion and Future Works}

Information technologies and systems take a key role within an organization. Organizations are more dependent on IT than ever before and different challenges in management and governance of IT functions have emerged. The goal of achieving a high degree of IT/business alignment has been one of the top priorities for IT professionals in academic and industry world for several years. Therefore, there are a lot of concerns in regard to the IT governance frameworks. These frameworks should support the contribution of IT to the overall value of the enterprise.

There is no single IT governance model that fits all businesses. The choice of model depends on multiple factors. Many of the existing frameworks are complementary, with strengths in different areas. They overlap each other and an organization will probably use more than one framework to achieve a complete model. Effective implementation of the frameworks demands significant changes in the organization and in its processes. It is necessary to understand in depth framework's complex structure and purpose with the aim to analyze, adapt, compare and 
integrate different frameworks of IT best practice. Hence, metamodeling can be a good starting point for enterprise specific governance model adaptation and configuration.

We used metamodeling as methodology for adaptation and customization of frameworks on a specific IT performance management domain. IT performance management requires careful preparation and planning, by following set of rules and best practices. It starts by defining what is important to measure and what the goals to be achieved are. Afterwards, it is important to continue with monitoring of progress towards defined goals for permanent improvement.

In this paper, we analyzed IT governance best practice frameworks and their semantic metamodels based on the existing literature. We provided same initial observation on conceptual models and ontologies, underlying the importance of understanding the logical structure of IT governance best practice frameworks for planning successful model integration. The approach of creating ontological metamodels supports comparison and integration of different IT governance frameworks in order to meet the semantic integration challenges. VAL IT and COBIT frameworks are closely related, having the different purposes. VAL IT is addressing strategic and evaluation questions, while COBIT is more oriented on IT architecture and the delivery of high quality IT services. By exhibiting the entity types and associated relationship types of VAL IT framework, we captured points of overlapping among these frameworks and moreover the key areas where they complement each other in order to use strengths of both models.

The main contribution of this work is reflecting through the creation of ontology metamodel of IT performance management framework. Through the model definition the underlying logical and semantically rich structure of the framework was represented. It was examined from different viewpoints, adjusted to conceptual level and improved through the elimination of substantial overlapping, supporting complex structures and relationships amongst entities. Our work captured the knowledge of best practice guidance in creating the business value of information technologies investments focusing on their performance. The resulting metamodel is seen as the first step in building specific enterprise governance model and it is essential to complement it with the knowledge of other frameworks.

In future studies, the methamodel will be adapted on the processes and structures of an organization. It will be used in developing application for monitoring IT performance. It should complete models of IT governance best practices to address in a comprehensive way all critical questions regarding the IT performance.

\section{Acknowledgements}

This research was partially supported by the Ministry of Education and Science, Republic of Serbia, Project number TR36006.

\section{Bibliography}

[1] Andra, S. (2006); Action-Oriented Metrics for IT Performance Management, Cutter IT Journal, 19(4): 17-21. http://www.cutter.com/content-and-analysis/journals-andreports/cutter-it-journal/sample/itj0604d.html

[2] Atkinson, C.; Kühne T. (2003); Model-Driven Development: A Metamodeling Foundation, In IEEE Software, 20(5): 36-41.

[3] Brandabur, R.E. (2013); IT Outsourcing - A Management-Marketing Decision, International Journal of Computers Communication and Control, ISSN 1841-9836, 8(2): 184-195. 
[4] Broussard, F.W.; Tero, V. (2007); Configuration and Change Management for IT Compliance and Risk Management: The Tripwire Approach, White Paper.

[5] Engels, G.; Gogolla, M.; Hohenstein U.; Hülsmann, K.; Löhr-Richter, P.; Saake, G.; Ehrich, H.-D. (1992); Conceptual Modelling of Database Applications Using an Extended ER Model, Data 83 Knowledge Engineering, ISSN 0169-023X, 9(2): 157-204.

[6] Franke, U. et al. (2009); Decision Support oriented Enterprise Architecture Metamodel Management using Classification Trees, Proceeding of Enterprise Distributed Object Computing Conference Workshops, EDOCW, Auckland, New Zealand, 328-335.

[7] Goeken, M.; Alter, S. (2009); Towards Conceptual Metamodeling of IT Governance Frameworks Approach-Use-Benefits, Proceeding of 42nd Hawaii International Conference on System Sciences HICSS, Hawaii, USA, ISSN 1530-1605, 1-10.

[8] Gu, B.; Xue, L.; Ray, R. (2008); IT Governance and IT Investment Performance: An Empirical Analysis, Proceedings of International Conference on Information Systems ICIS, http://aisel.aisnet.org/icis2008/30

[9] Haanappel, S.; Drost R.; Harmsen, F.; Brinkkemper, S.; Versendaal, J.M. (2011); A framework for IT performance management, http://www.cs.uu.nl/research/techreps/repo/CS2011/2011-006.pdf

[10] Information Technology Governance Institute (2005); Measuring and Demonstrating the Value of IT, USA, White paper.

[11] Information Technology Governance Institute (2007); COBIT 4.1 Edition, USA, White Paper.

[12] Jacobson, D.D. (2009); Revisiting IT Governance in the Light of Institutional Theory, Proceeding of 42nd Hawaii International Conference on System Sciences, HICSS, Hawaii, USA, $1-9$.

[13] Karagiannis, D.; Höfferer, P. (2008); Metamodeling as an integration Concept, Software and Data Technologies, In: Springer Berlin Heidelberg, 37-50.

[14] Kifor, V.C.; Tudor, N. (2013); Quality System for Production Software as Tool for Monitoring and Improving Organization KPIs, International Journal of Computers Communication E Control, ISSN 1841-9836, 8(2): 235-246.

[15] OGC 2007, The official introduction to the ITIL service lifecycle, London, UK: The Stationery Office, White Paper.

[16] Pereira R.; Mira da Silva M. (2012); A Literature Review: Guidelines and Contingency Factors for IT Governance, Proceeding in Mediterranean 8 Middle Eastern Conference on Information Systems, EMCIS, Munchen, Germany, 342-360.

[17] Saat, J. et al (2010); Enterprise Architecture Meta Models for IT/Business Alignment Situations, Proceeding of 14th IEEE International Enterprise Distributed Object Computing Conference, EDOC, Vitoria, Brazil, ISSN 1541-7719, 14-23.

[18] Silvius, A. J. G. et al (2013); The Relationship between IT Outsourcing and Business and IT Alignment: an Explorative Study, Computer Science and Information Systems, ISSN 1820-0214, 10(3): 973-998. 
[19] Simonsson, M.; Johnson, P. (2008); The IT Organization Modeling and Assessment Tool: Correlating IT Governance Maturity with the Effect of IT, Proceedings of 41st Annual Hawaii International Conference on System Sciences, HICSS, Hawaii, USA, pp. 431.

[20] Solow, R. (1987); "We'd better watch out", New York Times Book Review, pp. 36.

[21] Symons, C. (2005); IT Governance Framework, Forrester, White Paper.

[22] Webb, P. et al (2006); Attempting to Define IT Governance: Wisdom or Folly?, Proceeding in 39th Annual Hawaii International Conference on System Sciences, HICSS, Hawaii, USA, pp. 194a. 